\title{
DAMAGE MODELING IN GRADED LAYER SYSTEM
}

\author{
Michał PETAŚ, Krzysztof MRÓZ; , Krzysztof DOLIŃSKI* \\ *Reliability and Optimization, Department of Computational Science, IPPT PAN, ul. Pawińskego 5B, 02-106 Warszawa, Poland \\ mpetas@ippt.pan.pl, kmroz@ippt.pan.pl, kdolin@ippt.pan.pl
}

\begin{abstract}
The simplified approach to the modelling of low cycle fatigue (LCF) of functionally graded materials (FGM) based on the continuum mechanics is presented. The fatigue damage model takes into account the mechanical part of the load and a constant service temperature. The concept of FGM as a particle-reinforced metal-matrix composite with gradual change of the reinforcement fraction is used. The FGM is considered as a material consisting of homogeneous layers containing different volume fractions of the reinforcement. The variation of the reinforcement fraction changes the material properties for each layer. The different material properties are obtained according to modified rule of mixture. Since the fatigue damage of metal matrix composites is strongly influenced by the inelastic deformation of the metallic matrix, the constitutive equations of LCF damage model are taken into consideration. The combined isotropic/kinematic hardening model with linear behaviour of isotropic and kinematic parts of hardening is adopted. The damage scalar parameter is associated with the plastic energy dissipation which is used to update the material properties. The fatigue damage model presented in this paper is applied to the fatigue damage analysis of the cooling channel of thruster used in space shuttles and rockets.
\end{abstract}

Key words: Fatigue Damage, Low Cycle Fatigue, Functionally Graded Materials, Layers

\section{INTRODUCTION}

The main objective of this work is to present the damage model of the Low Cycle Fatigue (LCF) for a special kind of Particle-Reinforced Metal-Matrix Composites (PR-MMC) with heterogeneous structure. This heterogeneity is assumed to be distributed in one direction within the entire volume of a material. These materials known as Functionally Graded Materials (FGMs) are a new class of the composites that have been developed recently for various engineering applications. The application of this concept to PR-MMC leads to the development of materials/components designed with the purpose of being selectively reinforced only in regions requiring increased strength and/or wear resistance. It extends essentially the industrial applications of the considered materials.

Most of structural elements are subjected to cyclic loading under service conditions. The elaboration of the methods to fatigue life analysis of FGMs is a challenge for modern industry, because the problem of the cumulative fatigue damage has not been resolved yet despite the fact that the history of fatigue damage modeling is dated back to 1920 s and 1930s. Therefore, the attention in this paper is devoted to the numerical modeling of low cycle fatigue induced by mechanical loading. The damage model of LCF is based on the accumulated plastic strain energy dissipation. On the assumption that the stresses in LCF are close or above the yield limit and global plasticity will be dominating cause of fatigue damage in FGMs, the linear isotropic/kinematic hardening model in combination with the Huber-von Misses yield surface is used to calculate plastic energy dissipation for each loading cycle. On the basis of the energy approach, the damage parameter $D$ is calculated. Use of the damage parameter is aimed at updating the material properties to simulate cyclic behaviour of FGM composite. The micro-structural parameters, such as the volume fractions are taken into account to calculate material properties of FGM composite. The FGM is considered as a material consisting of homogeneous layers containing different volume fractions of the reinforcement. The fatigue damage model presented in this paper is applied to fatigue damage analysis of cooling channel of thruster used in space shuttles and rockets with the assumption that delamination of layers is not possible.

\section{APPROACHES TO FATIGUE DAMAGE}

Palmgren (1924) was the first who introduced the concept of linear summation of fatigue damage. This concept known as Linear Damage Rule (LDR) was represented first time in mathematical form by Miner (1945). In the LDR the measure of damage is simply the cycle ratio with a basic assumption of the constant work absorption per cycle and characteristic amount of work absorbed at failure. The energy accumulation, therefore, leads to a linear summation of cycle ratio or damage. The main deficiencies with LDR are its load-level independence, load-sequence independence and lack of load-interaction accountability. Machlin (1949) proposed a metallurgically based cumulative theory which is basically another form of LDR. In 1950s, Coffin and co-workers (Coffin, 1956; Baldwin et al., 1957) expressed the LDR in terms of plastic strain range which is related to fatigue life though the Coffin-Manson relation. However, due to the inherent deficiencies of the LDR, no matter which version is used, life prediction based on this rule is often unsatisfactory. To remedy the deficiencies associated with LDR Richart and Newmark (1948) introduced the concept of damage curve and speculated that such curve of damage parameter and cycle ratio ought to be different at different stress-levels. Upon this concept and the results of load sequence experiments, Marco and Starkey (1954) proposed in 1954 the first nonlinear load-dependent damage theory represented by a power relationship. 
Next concept of fatigue damage is theory based on endurance limit reduction. French (1933) was the first who reported the significant investigation of the overstress effect on endurance limit. In 1938 Kommers (1945) and Bennet (1946) suggested the change of the endurance limit as a damage measure but they did not correlate this measure to the life fraction. This kind of correlation was for the first time deduced by Henry (1955) and later by Gatts (1961, 1962) and Bluhm (1962). All of these damage models based on endurance limit reduction are nonlinear and able to account for the load sequence effect. None of these models take into account load interaction effects. Early theories accounting for load interaction effects are based on Corten-Dolon model (Corten and Dolon, 1956) and Freudenthal-Heller (Freudenthal, 1956; Freudenthal and Heller, 1956) approach. Both theories are based on the modification of the stress-cycles diagram, which is simply a clockwise rotation of the original stress-cycles line. Langer (1937) was the first who proposed to separate the fatigue damage process into two stages, namely: the crack initiation and crack propagation. The linear rule was proposed for each stage. Following Langer's concept Grover (1960) considered cycle ratios for two separate stages in the fatigue damage process under constant stress amplitude. Manson (1966) reverted to Grover's work and proposed the Double Linear Damage Rule called DLDR.

Another approach in cumulative fatigue damage analysis is the crack growth concept. On the basis of the mechanism of progressive unbounding of atoms as a result of reversed slip induced by stress cycling Shanley (1952) introduced a damage theory by defining crack length as measure. It was suggested that the crack growth rate varies with the applied stress level in either a linear or an exponential manner. Valluri (1961a, b) presented a crack growth damage model in a differential form. The quantitative develoment of the theory is based on concepts derived from dislocation theory and a synthesis of the macroscopic elastoplastic fracture theory. On the basis of the DLDR and crack growth approaches Manson and Halford (1981) presented damage curve approach (DCA) to refine the original DLDR through a reliable physical basis. They empirically formulated the 'effective crack growth' model based on phenomenological recognition that the major manifestation of damage is crack growth which involves many complicated processes such as dislocation agglomeration, subcell formation, multiple micro-crack formation and the independent growth of these cracks until they link and form a dominant crack. Manson and Halford and co-workers (Bizon et al., 1985; Halford and Manson, 1985; Manson and Halford, 1981, 1983) developed DCA approach by adding a linear term to the DCA equation with some mathematical manipulation and called it Double-Damage curve model (DDCA). The models developed by Manson and Halford are all load-level dependent, but do not account for the load interaction effect and small-amplitude cycle damage. In 1971 Bui-Quoc and colleagues presented their work dealing with cumulative fatigue damage under stress-controlled (Bui-Quoc, 1981) and strain-controlled (Bui-Quoc et al., 1971) conditions. Both theories were combined into 'unified theory' (Dubuc et al., 1971). The theory for stress-controlled fatigue was first developed from the hybridization of four prior damage models by Henry (1955), Gatts (1961), Shanley (1952) and Valluri (1961). Bui-Quoc and coworkers (Bernard-Connolly, 1983; Biron and BuiQuoc, 1981; Bui-Quoc, 1981, 1982 a,b) modified their damage models to account for the load interaction effect under cyclic loading involving several stress levels. After the early 1970s, new fatigue damage theories have been developed based on the microcrack grow concept. Most of these newer models better explain the physics of the damage than those developed before 1970s. A popular macro fatigue crack growth retardation model (Wheeler, 1972) is formulated by Wheeler. This model assumes the crack growth rate to be related to the interaction of crack-tip plastic zones under residual compressive stresses created by overloads. A similar model based on crack tip plasticity is Willenborg model (Willenborg et al., 1971). This model uses an effective stress intensity factor at the crack tip to reduce the applied crack tip stress intensity factor due to the increased crack tip residual compressive stress induced by the overloads.

Next fatigue damage concept is energy based approach. Since Inglis presented the report (Inglis, 1927) of connection between hysteresis energy and fatigue behaviour many studies on energy methods have been carried out. Several failure criteria based on strain energy were established by Morrow (1965), Halfrod (1966), Glinka et al. (1995), Lagoda (2001), Seweryn et al. (2008), Zuchowsky (1989) and Leis (1997). Some energy-based damage parameters have been proposed. It has been realized that an energy-based damage parameter can unify the damage caused by different types of loading such as thermal cycling, creep, and fatigue. Energy-based damage models can also include mean stress and multiaxial loads since multiaxial fatigue parameters based on strain energy have been developed. Kujawsky and Ellyin [38] developed a damage model by using plastic strain energy density as a parameter. It was later found that some inefficiency were associated with plastic strain energy approach. For example, the effect of mean stress cannot be directly incorporated in the determination of the hysteresis energy. Also, for the low strain high-cycle fatigue, the plastic strain energy density is very small. In some cases the macroscopic (bulk) response of the material is elastic or quasi-elastic, microscopic (local) plastic deformation may still exist in the material due to the nonuniformity of local strain distribution and/or due to the strain concentration by high prestraining. Golos and Ellyin (1987, 1988, 1989) modified the plastic strain energy-based model using total strain energy density. The total strain energy density combines both plastic and elastic portions. The elastic portion is thought to be associated with the tensile mode and can facilitate crack growth. A power function analogous to stress-cycles relation is employed to describe the energy-life relation, which is a straight line in a log frame. Leis (1988) proposed an energy-based nonlinear history-dependent damage model which links the damage parameter to fatigue life. He speculated that the instantaneous strain-hardening exponent can be characterized as a function of accumulation of plastic strain. The model created by Leis is therefore an analytical formulation in terms of the deformation history. Clearly, properly defining the function of strain-hardening exponent is crucial in the application of this damage model. Niu (1987) and Niu et al. (1987) found the cyclic strain hardening coefficient to change during the cyclic process while the cyclic strain hardening exponent had a negligible change. In this model, the energy accumulation is defined by introducing a parameter called fraction of plastic strain energy. The model represented by Niu et al. is a nonlinear, load-dependent damage accumulation model. It accounts for the load interaction effect and the change in strain hardening through the stress response. This model is especially suitable for materials which exhibit cyclic hardening. Radhakrishnan $[60,61]$ postulated that the crack growth rate is proportional to the plastic strain energy density which is linearly accumulated to failure. His formulation of damage equation implies that failure occurs when the accumulated plastic energy reaches the value of total plastic energy in the last loading stage 
under constant amplitude cycling. This implication excludes the influence of load interaction effect on total plastic energy.

Another approach of fatigue damage is based on Continuum Damage Mechanics (CDM). CDM deals with the mechanical behavior of a deteriorating medium at the continuum scale. This approach is developed based on the original concepts of Kachanov (1969) and Rabotnov (1969) in treating creep damage problems. The success of CDM application in modelling the creep damage process has encouraged many researches to extend this approach to ductile plastic damage, creep-fatigue interaction, brittle fracture and fatigue damage. In addition to metallic materials CDM can also be applied to composites and concrete materials. Chaboche (1974) postulated that fatigue damage evolution per cycle for one-dimensional case can be generalized by a function of the load condition and damage state. Tests conducted under completely reversed strain-controlled conditions provided supportive information. By measuring the changes in tensile loadcarrying capacity and using the effective stress concept he formulated a nonlinear damage evolution law (Chaboche, 1974, 1982). This damage model is highly nonlinear in damage evolution and is able to account for the mean stress effect. It is, therefore, called a Nonlinear-Continuous-Damage (NLCD) model (Chaboche and Lesne, 1988). This model has three main advantages. First, it allows for the growth of damage below the initial fatigue limit, when the material is subjected to prior cycling above the fatigue limit (Chaboche and Lesne, 1988). Second, the model is able to take into account the influence of initial hardening effect by introducing a new internal variable which keeps memory of the largest plastic strain range in the prior loading history (Chaboche and Kaczmarek, 1981; Chaboche and Lesne, 1988). Third, mean stress effect is directly incorporated in the model. Based on the CDM concept, many other forms of fatigue damage equations have been developed after Chaboche's work (Chaboche, 1974). Such models include those proposed by Lemaitre and Chaboche $(1978,1990)$, Lemaire and Plumtree (1979) and Li et al. (1989). Basically, all these CDM-based approaches are very similar to Chaboche NLCD model in both form and nature. The main differences lie in the number and the characteristics of the parameters used in the model, in the requirements for additional experiments, and in their applicability. Socie and co-workers (Socie, 1983; Weinacht and Socie, 1987) applied the Lemaitre-Plumtree model to the fatigue damage analysis of cast iron to account for the influence of defects on fatigue life. They reported improved life predictions as compared to the Miner rule (Socie et al., 1983). Plumtree and O'Connor (1989) attempted to analyze damage accumulation and fatigue crack propagation in aluminum alloy using a modified Lemaitre-Plumtree model. Hua and Socie (1984) also evaluated the Chaboche and Lemaitre-Plumtree models in their investigations of biaxial fatigue. They found the Chaboche model to be better than Lemaitre-Plumtree model for fatigue damage assessment.

Though many damage models have been developed, unfortunately, none of them enjoys universal acceptance. Each damage model can only account for one or several phenomenological factors, such as load dependence, multiple damage stages, nonlinear damage evolution, load sequence and interaction effects, overload effects, small amplitude cycles below fatigue limit and mean stress. Due to the complexity of the problem none of the existing predictive models can encompass all of these factors. Therefore, more efforts in the study of cumulative fatigue damage are needed in order to provide design engineers with a general and reliable fatigue damage analysis and life prediction model.

\section{MODEL DESCRIPTION}

\subsection{Flow Hardening and Damage Rules}

The fatigue damage concept presented in this paper is developed by using micromechanical and continuum mechanics approaches in combination with Finite Element Method. Implementation of the damage model is made in Abaqus UMAT subroutine. The gradual change in composite is modelled by assuming that the FGM material consists of layers of the various volume fraction of the uniformly distributed reinforcement. The same sizes of reinforcement particles within each layer are assumed.

Low cycle fatigue damage of metal matrix composites is strongly influenced by the inelastic deformation in metallic matrix (LLorca, 2002). Therefore, the constitutive equations of LCF damage model take into account the most important effects of inelastic deformation, such as the increase of yield stress with rising deformation, rate- and time-dependency, yield stress reduction after a change of the straining direction known as Bausinger-effect and the hysteresis loops resulting from cyclic loadings conditions. The model consists of elastic and plastic constitutive laws in the context of infinite deformation theory. Elasticity is considered isotropic and linear. Simulation of plasticity effects is possible by using the combined isotropic/kinematic hardening model with linear behaviour of isotropic and kinematic parts of hardening. This feature is particularly appropriate for applications to cyclic plasticity within an individual cycle where kinematic hardening is the dominant hardening process reflected in the Bauschinger effect, but over quite large numbers of cycles the material also hardens isotropically leading to the eventual saturation of the inelastic energy (Dunne and Petrinic, 2005). The hardening model is used in combination with the Huber-von Misses Yield criterion which is applicable for analysis of plastic deformation for ductile materials such as metals. It can be also adapted to metal-matrix composites. On the basis of Huber-von Misses criterion the effective stress is determined to identify the yield condition for multiaxial load. If this stress is equal or greater than yield stress then the material yields. Otherwise, the material behaviour is elastic. The effective stress is obtained from the following equation:

$\sigma_{e}=\sqrt{\frac{3}{2}\left(S_{i j}-\alpha_{i j}\right):\left(S_{i j}-\alpha_{i j}\right)}$,

where: $\sigma_{e}$ - is the equivalent stress, $S_{i j}$ - denotes the stress deviator tensor, $\alpha_{i j}$ - is the shift tensor (backstress tensor).

The Huber-von Misses yield criterion for combined hardening model is defined by:

$f=\sigma_{e}-r-\sigma_{y}=0$,

where: $f$ - yield function, $r$ - isotropic hardening function, $\sigma_{y}$ - initial yield stress of a composite material obtained from static tensile characteristics. After substituting eq. (1) to eq. (2) the yield function becomes:

$f=\sqrt{\frac{3}{2}\left(\mathrm{~S}_{\mathrm{ij}}-\alpha_{\mathrm{ij}}\right):\left(\mathrm{S}_{\mathrm{ij}}-\alpha_{\mathrm{ij}}\right)}-r-\sigma_{y}=0$.

When the plastic deformation occurs $(f=0)$ and loading continues the associated plastic flow law determines the direction of increment of the plastic strain tensor. This direction is normal to the yield surface at the load point. The equation of the associ- 
ated plastic flow law is written as follows:

$\dot{\varepsilon}^{p}=\dot{\lambda} \frac{\partial f}{\partial \sigma}=\dot{\lambda} \cdot \nabla f, d \varepsilon^{p}=d \lambda \frac{\partial f}{\partial \sigma}=d \lambda \cdot \nabla f$,

where: $\dot{\varepsilon}^{p}$ - plastic strain rate, $\dot{\lambda}$ - plastic multiplier (strain rates), $d \varepsilon^{p}$ - plastic strain increment, $d \lambda$ - plastic multiplier (strain increments), $\nabla f$ - direction of the plastic strain increment. The equation of plastic flow can be written in terms of the deviatoric stress, equivalent stress and equivalent plastic strain:

$\dot{\varepsilon}^{p}=\frac{3}{2} \dot{\varepsilon}^{e q} \frac{s}{\sigma_{e}}, d \varepsilon^{p}=\frac{3}{2} d \varepsilon^{e q} \frac{s}{\sigma_{e}}$,

where: $\dot{\varepsilon}^{e q}$ - equivalent plastic strain rate, $d \varepsilon^{e q}$ - equivalent plastic strain increment, $\boldsymbol{S}$ - deviator of a stress tensor. The equations of equivalent plastic strain rate and equivalent plastic increment are given in following forms:

$\dot{\varepsilon}^{e q}=\sqrt{\frac{2}{3} \cdot \dot{\varepsilon}^{p}: \dot{\varepsilon}^{p}}, d \varepsilon^{e q}=\sqrt{\frac{2}{3} d \varepsilon^{p}: d \varepsilon^{p}}$,

where: $\dot{\varepsilon}^{p}$ - plastic strain rate tensor, $d \varepsilon^{p}$ - plastic strain increment tensor.

During LCF loading, energy is absorbed mainly because of plastic deformation. The majority of this mechanical energy is converted into heat while the remaining part of the energy causes damage in the material. The magnitude of damage experienced by the material during fatigue cycles is strongly dependent on the loading inputs and fatigue resistance of the material and is directly related to the material capacity for absorption of the energy input (Sutton, 2009). Determination of the plastic cyclic strain energy for described model is based on the tensile characteristics and calculated equivalent data. On the basis of the plastic energy dissipation the fatigue damage parameter is determined to describe the cyclic behaviour of composite.

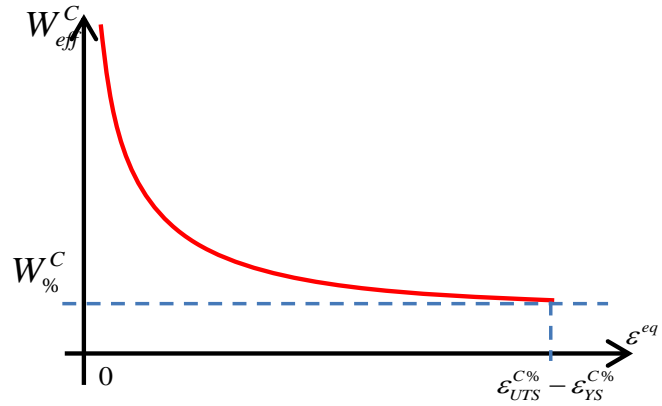

Fig. 1. The critical dissipation energy values function.

Calculation of the increment of damage parameter $(D)$ is based on the following equations:

$d D=\frac{1}{W_{e f f}^{C}} d W=\frac{1}{f\left(\varepsilon^{e q}\right) W_{\%}^{C}} d W=\frac{1}{\left(1+\ln \frac{\varepsilon_{U T S^{C}-\varepsilon_{Y S}^{C \%}}^{C \%}}{\varepsilon^{e q}}\right) W_{\%}^{C}} d W$,

where $d W$ is the increment of the plastic strain energy density and can be written as:

$d W=\sigma_{e} d \varepsilon^{e q}$,

$W_{e f f}^{C}$ is the disspation energy value function (Fig. 1), $W_{\%}^{C}$ - is the critical value of the dissipation energy calculated on the basis of the monotonic tensile stress-strain curve and $\varepsilon_{U T S}^{C \%}, \varepsilon_{Y S}^{C \%}$ are the monotonic composite strain values (Fig. 4). When monotonic tensile loading is applied $f\left(\varepsilon^{e q}\right)=1$ and $W_{e f f}^{C}=W_{\%}^{C}$.

The simulation of cyclic behaviour is possible by updating data of static tensile characteristics (Fig. 2) for a point of the material in which damage occurs. The updating operation is performed at the beginning of every loading cycle. All peak stress values (yield stress, ultimate tensile stress) are updated as follows:

$\sigma_{i}=\sigma_{i-1}\left(1-D_{i}\right)$,

where: $\sigma_{i}$ - updated peak stress value, $\sigma_{i-1}$ - previous peak stress value while the tangent modulus is kept constant. The drop in peak values follows accumulated damage which is calculated from the following equation:

$D_{i}=D_{i-1}+\Delta D_{i-1}$,

where: $D_{i}$ - accumulated damage in current cycle, $D_{i-1}-$ accumulated damage from previous cycle, $\Delta D_{i-1}$ - damage increment from previous cycle (associated with energy dissipation in each cycle). If the parameter $D$ reaches the unit value then failure occurs in the material element.

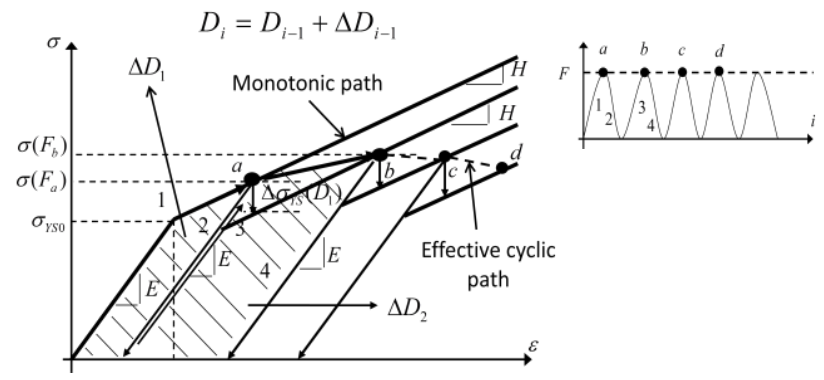

Fig. 2. The cyclic curve with damage approximation

\subsection{Effective Stiffness and Hardening Moduli}

Stress-strain curve and properties of a composite material are obtained on the basis of modified rule of mixture, named TTO (Tamura-Tomota-Ozawa) (Tamura et al., 1973), related to the spatial distribution of its components and adapted to FGMs by Williamson et al. (1993).

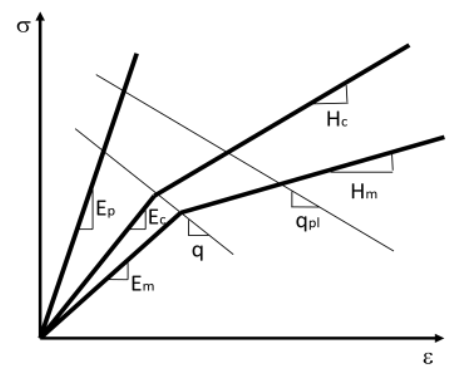

Fig. 3. Stress-strain curves for FGM system using mixture theory

The TTO model relates the uniaxial stress and strain of a twophase composite, (Fig. 3), to the corresponding average uniaxial stresses and strains of the two constituent materials by:

$\sigma=V_{p} \sigma_{p}+V_{m} \sigma_{m}, \varepsilon=V_{p} \varepsilon_{p}+V_{m} \varepsilon_{m}, V_{p}+V_{m}=1$,

where: $\sigma_{i}$ and $\varepsilon_{i}(i=p, m)$ - are the average stresses and strains of constituent phases, respectively, $V_{i}(i=p, m)$ - the 
volume fractions of constituent phases. In the TTO mode an additional parameter $q$ is introduced which represents the ratio of stress to strain transfer:

$q=\frac{\sigma_{p}-\sigma_{m}}{\left|\varepsilon_{p}-\varepsilon_{m}\right|}$

where: $q$ - ratio of stress to strain transfer.

The value of the $q$ parameter depends on the constituent material properties and the microstructural interaction in the composite. For example, $q \rightarrow \infty$ if the constituent elements deform identically in the loading direction, while $q=0$ if the constituent elements experience the same stress level. In general, the constituent elements in a composite undergo neither equal strain nor equal stress due to the complicated microstructure (variations in particle shape, orientation, volume fraction and so on). A nonzero finite value of $q$ approximately reflects those effects. Note that:

$\sigma_{i}=E_{i} \varepsilon_{i}$

where: $E_{i}(i=p, m)$ - Young's moduli of the constituent phases. Then:

$\frac{\varepsilon_{p}}{\varepsilon_{m}}=\frac{q-E_{m}}{q-E_{p}}$

or

$\frac{\sigma_{p}}{\sigma_{m}}=\frac{E_{p} E_{m}-q E_{p}}{E_{p} E_{m}-q E_{m}}$

The Young's modulus of the composite may be obtained as follows:

$E^{C \%}=\frac{\sigma}{\varepsilon}=\frac{V_{p} E_{p} \frac{q-E_{m}}{q-E_{p}}+V_{m} E_{m}}{V_{p} \frac{q-E_{m}}{q-E_{p}}+V_{m}}$,

where: $E^{C \%}$ - Young's modulus of the composite. The Poisson ratio of the composite $v$ just follows a rule of mixtures in the TTO model:

$v=v_{p} V_{p}+v_{m} V_{m}$

where: $v_{i}(i=p, m)$ - Poisson's ratio of the constituent phases. For applications involving plastic deformation of ceramic/metal (brittle/ductile) composites the TTO model assumes that the composite yields once the metal constituent yields. The yield stress of the composite, $\sigma_{Y S}^{C \%}$, is thus determined as follows:

$\sigma_{Y S}^{C \%}=V_{p} \sigma_{p}+V_{m} \sigma_{Y S}^{m}=\sigma_{Y S}^{m}\left[V_{m}+\frac{E_{m}-q}{E_{p}-q} \frac{E_{p}}{E_{m}}\left(1-V_{m}\right)\right]$,

$\varepsilon_{e l}^{C \%}=\sigma_{Y S}^{C \%} / E^{C \%}$,

where: $\sigma_{Y S}^{m}$ - yield stress of the metal matrix. The above equation indicates that the yield stress of the composite depends on the yield stress of the metal matrix, the volume fraction of the metal, the Young's moduli of the constituent phases, and the parameter $q$. Carpenter et al. (1993) chose arbitrarily a $q$ value equal to 4.5 GPa for Ti/TiB FGM system. This value has been previously used for dual phase steels and $\mathrm{Al}_{2} \mathrm{O}_{3}-\mathrm{Ni}$ (Williamson et al., 1993). Ideally this parameter should be determined experimentally from the uniaxial stress-strain curve for composite.

Since the ratio of stress to strain transfer for plastic behaviour of matrix is changing, it is postulated to use the second stress to strain transfer parameter as $q_{p l}$. Then the tangent modulus of composite follows a bilinear response as:

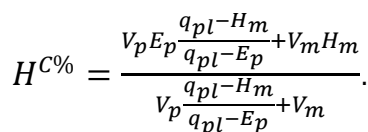

If the value of tangent modulus $H^{C x}$ (Fig. 4), for one composite (two material with different relation) is known it is possible to calculate $q_{p l}$ parameter and to obtain $H^{C y}$ for different combination of consistent materials. Consequently, the ultimate tensile stress, $\sigma_{U T S}^{C \%}$ can be approximated by:

$\sigma_{U T S}^{C \%}=V_{p} \sigma_{U T S}^{p}+V_{m} \sigma_{U T S}^{m}$

and

$\varepsilon_{U T S}^{C \%}=\frac{\varepsilon_{e l}^{C \%} H^{C \%}+\sigma_{U T S}^{C \%}-\sigma_{Y S}^{C \%}}{H^{C \%}}$.

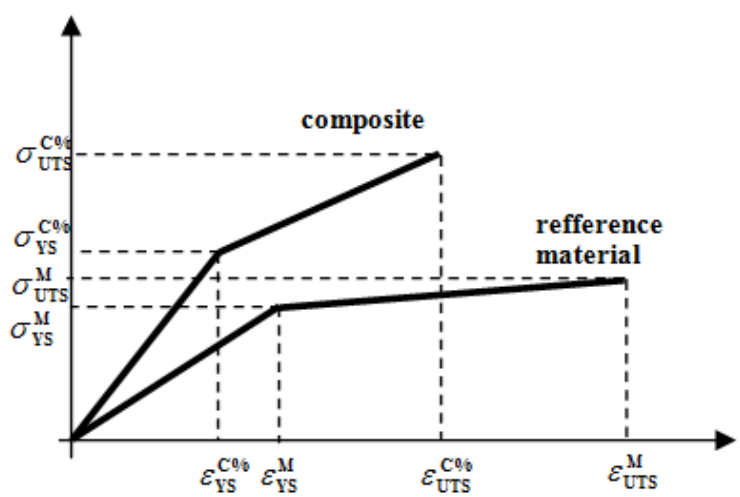

Fig. 4. Stress-strain curves for different combination of consistent materials

\section{MODEL APPLICATION}

In the aerospace thruster application the currently used material is CuAg3Zr0.5 alloy (no gradient). Fine channels are milled in the thruster basic structure for transporting the fuel (liquid oxygen and hydrogen) as cooling agents (Fig. 5). Unfortunately, in the structures the thinning of the cooling passage wall, bulging of the wall toward the thrust chamber centerline and, finally, failure by a crack ('dog-house' failure mode) is observed under the cyclic plastic deformation at elevated temperature, (Fig. 6). Consequently, the analysis of the single loading is not sufficient for the prediction of the life time of thrusters and the fatigue analysis is needed. In the UE MATRANS project it was proposed to use FGM materials $\left(\mathrm{Al}_{2} \mathrm{O}_{3}-\mathrm{Cu}\right)$ with gradually changing volume fraction of alumina within $\mathrm{Cu}$ matrix as depicted in Fig. 5. The advantage of FGM solution is that by the gradual alumina contents the thermal stresses in the thruster inner wall can be reduced due to different thermal expansion while improving a number of key properties.

In the Tab. 1 the effective experimental and predicted material parameters are presented for the room temperature (RT) and $700 \mathrm{~K}$ based on the mixture theory.

In order to illustrate the evolution of the fatigue damage process under mechanical cyclic loading in the constant high temperature $(700 \mathrm{~K})$ a comparison between the references material $\mathrm{CuAg} 3 \mathrm{ZrO} .5$ and graded material $\mathrm{Al}_{2} \mathrm{O}_{3}-\mathrm{Cu}$ was made by using the fatigue damage model described in the chapter 3 and the mechanical loading based on Andrews and Armstrong (1974) data (Fig. 8). In Fig. 7 an examined part of the structure is shown. The maximum of the loading conditions (temperature and pressure) for time 2.25 s was assumed as a critical one. 


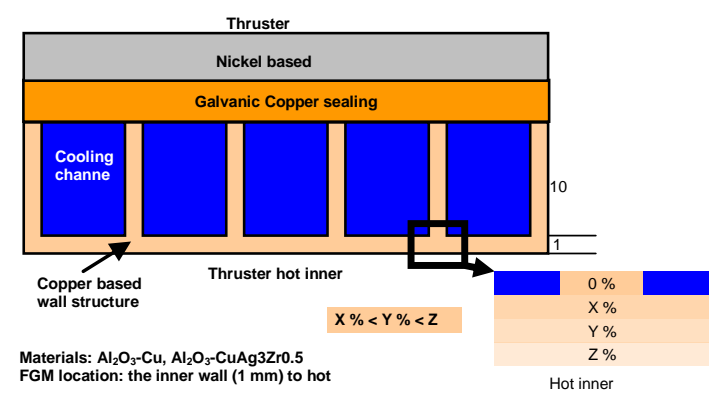

Fig. 5. Basic principle of thruster structure and the proposed FGM solution
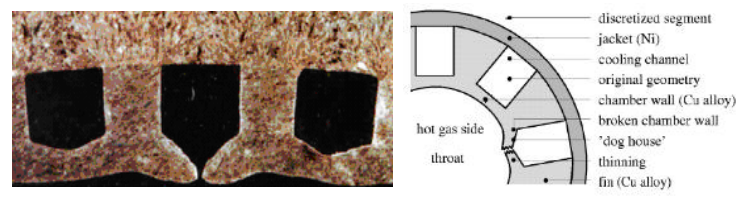

Fig. 6. 'Dog-house' failure mode

Tab. 1. The effective experimental (underlined) and predicted material parameters for the room temperature (RT) and $700 \mathrm{~K}$ based on mixture theory

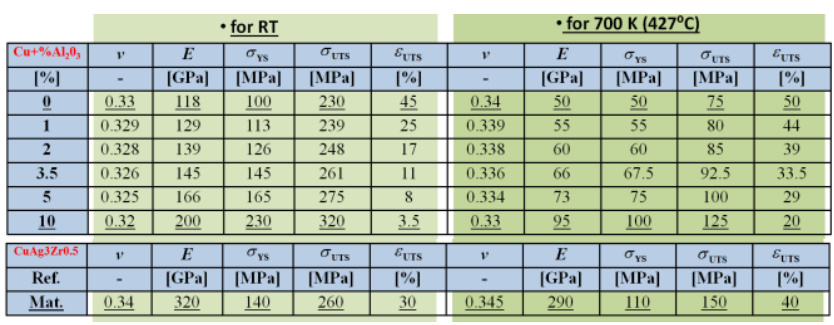

*The underlined results were obtained by EADS Innovation Works within the EU FP7 Project 'MATRANS'.

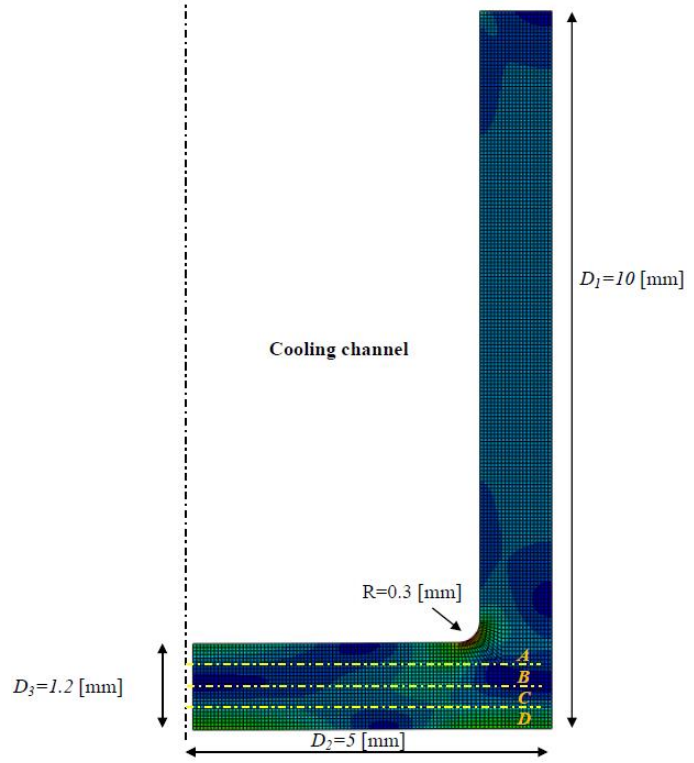

Fig. 7. The considered part of the thruster

The considered part of the thruster consists of 4 parts of materials. The part $A$ is made of the base matrix material (OFHC Copper), the layers B, $C$ and $D$ contain $2 \%, 3 \%$ and $5 \%$ of the ceramic particles $\left(\mathrm{Al}_{2} \mathrm{O}_{3}\right)$, respectively. The calculations show that the number of cycles to first failure of any single element $\left(N_{i n}\right)$ in the graded structure is equal to $39,7 \%$ of that number for the references material, i.e.

$q=\frac{N_{\text {in }}}{N_{\text {in } R e f}} 100 \%=39,7 \%$,

where: $N_{\text {in }}$ - number of cycles to first failure of an element in the graded structure, $N_{\text {inRef }}-$ number of cycles to first failure of an element in the references material (CuAg3Zr0.5 alloy).
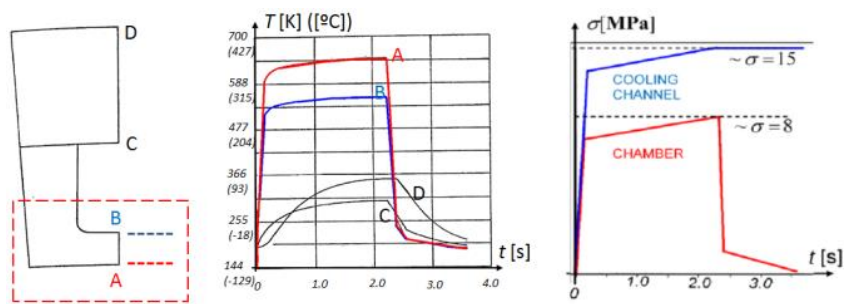

Fig. 8. The thermal-mechanical loading cycle, based on Andrew and Armstrong (1974)

In Fig. 9 the damage comparsion between the references material and the graded material is presened. In the initial phase of the fatigue process the fatigue damage is localized mainly in the corner of the cooling channel. Whereas the number of cycles to total failure of the considered structure associated with the damage of all elements across the structure section $\left(N_{f}\right)$ appears to be much smaller than that number for the reference material.

\section{CONCLUSIONS}

The presented analysis is aimed at application of the simplified approach based on the continuum mechanics to modelling of the low cycle fatigue of functionally graded materials. The simulation of cyclic behaviour is assumed as updating data of static tensile characteristics for a point of the material in which damage occurs. All peak stress values (yield stress, ultimate tensile stress) are reduced follows accumulated damage rule associated with the plastic energy dissipation while the tangent modulus is kept constant.

The concept of FGM as a particle-reinforced metal-matrix composite with gradual change of the reinforcement fraction is used. The FGM is considered as a material consisting of homogeneous layers containing different volume fractions of the reinforcement. The variation of the reinforcement fraction changes the material properties for each layer. The different material properties are obtained according to modified rule of mixture.

The model was applied to the cooling channel of thruster used in space shuttles and rockets. The cooling system is actually subjected simultaneously to the thermo-mechanical loading. However, the mechanical cyclic loading was only considered at the constant maximum high temperature, $700 \mathrm{~K}$. The reasons for the "dog house" failure mode have been revealed. In the initial phase of the fatigue process the failure begins in the corner of the cooling channel. Next the damage appears at the inner hot surface and develops upwards towards the cold cooling channel. It leads to necking of the layer and results to totally failure of the cooling channel. In conclusion, the proposed FGM material 
structure shows the shorter mechanical fatigue life than reference $\mathrm{CuAg}_{3} \mathrm{Zr}_{0.5}$ material. a)

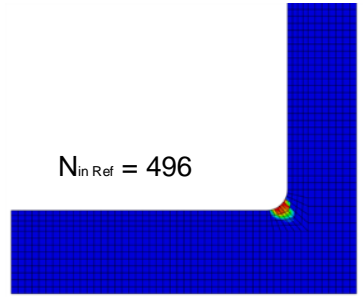

b)

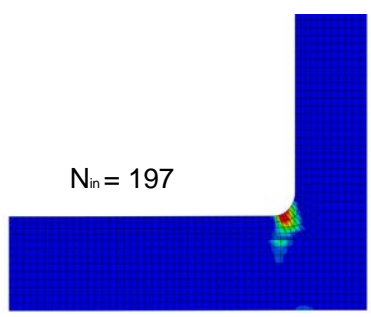

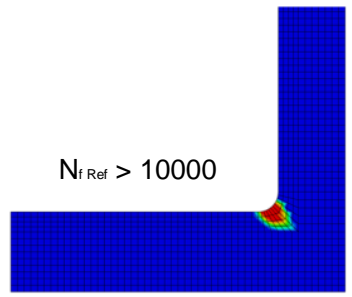

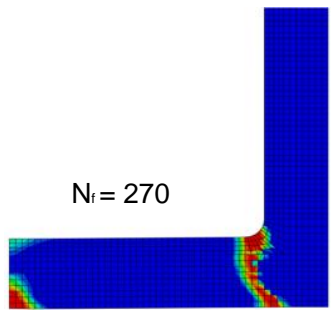

Fig. 9. The damage comparsion based on fatigue cycles between the references material and graded material: a) $\mathrm{CuAg}_{3} \mathrm{Zr}_{0.5}$. references material; b) $\mathrm{Al}_{2} \mathrm{O}_{3}-\mathrm{Cu}$ - graded material

It should be pointed out that in the analysis presented in this paper some material deterioration due to erosion and blanching, say, that developes during the thruster service life and could have a significant effect on the fatigue life time were not considered. Since the resistance of the layered $F G M$ with $\mathrm{Al}_{2} \mathrm{O}_{3}$ particles newly proposed for the thruster to those deteriorating actions is much greater than the resistance of the currently used $\mathrm{CuAg}_{3} \mathrm{Zr}_{0.5}$ material the relation between the actual fatigue life times for both materials might be quite different or even reversed to that given in Eq. (23).

\section{REFERENCES}

1. Andrews J.S., Armstrong W. H, (1974), Thrust Chamber Life Prediction, Boeing AeroSspace Company, (NASA-CB-144048).

2. Baldwin E. E., Sokol G. J., Coffin L. E (1957), Cyclic strain fatigue studies on AISI 347 stainless steel, Proceedings, American Society for Testing and Materials, 57, 567-586.

3. Bennett J. A. (1946), A study of the damaging effect of fatigue stressing on X4130 steel, Proceedings, American Society for Testing and Materials, 46, 693-714.

4. Bernard-Connolly M., Bui-Quoc T., Biron A. (1983), Multilevel strain controlled fatigue on a type 304 stainless steel, ASME Journal of Engineering Materials and Technology, 105, 188-194.

5. Biron A., Bui-Quoc T. (1981), Cumulative damage concepts with interaction effect consideration for fatigue or creep; a perspective, In Transactions of the 6th International Conference on Structural Mechanical Reaction Technology, Paris, France, L9/1.1-7.

6. Bizon P. T., Thoma D. J., Halford G. R. (1985), Interaction of high cycle and low cycle fatigue of Haynes 188 at $1400 \mathrm{~F}$, In Structure Integrity and Durability of Reusable Space Propulsion Systems, NASA CP-2381. NASA Lewis Research Center, Cleveland, OH, pp. 129-138.

7. Bluhm J. (1962), A note on fatigue damage, Materials Research and Standards.

8. Bui-Quoc T., Dubuc J., Bazergui A., Biron A. (1971), Cumulative fatigue damage under strain controlled conditions, Journal of Materials, 6, 3, 718-737.
9. Bui-Quoc T. (1981), An interaction effect consideration in cumulative damage on a mild steel under torsion loading, Proceedings of the 5th International Conference on Fracture, Pergamon Press, 5, 26252633.

10. Bui-Quoc T. (1982), Cumulative damage with interaction effect due to fatigue under torsion loading, Experimental Mechanics, 22, 180187.

11. Bui-Quoc T. (1982), A simplified model for cumulative fatigue damage with interaction effects, In Proceedings of the 1982 Joint Conference on Experimental Mechanics, Society for Experimental Stress Analysis, Brookfield Center, CT, 144-149.

12. Carpenter R. D., Rabin B. H., Drake J.T. (1993), Finite Element Analysis of Thermal residual Stresses at Graded Ceramic-Metal Interface, Part I. Model Description and Geometrical Effects, J. Appl. Phys., Vol. 74, 2, 13010-1320.

13. Chaboche J. L. (1974), A differential law for nonlinear cumulative fatigue damage, In Materials and Building Research, Paris Institut Technique Du Batiment Et Des Travaus Publies, Annales de I'ITBTP, HS No. 39, 117-124.

14. Chaboche J. L., Kaczmarek H. (1981), On the interaction of hardening and fatigue damage in the 316 stainless steel, In Proceedings of the 5th International Conference on Fracture (ICF 5), Cannes, Vol. 3, Pergamon Press, Oxford, 1381-1393.

15. Chaboche J. L. (1982), Lifetime predictions and cumulative damage under high-temperature conditioned, In Low-cycle Fatigue and Life Prediction, ASTM STP 770, eds. C, Amzallag, B. N, Leis and P. Rabbe, American Society for Testing and Materials, Philadelphia, PA, 81-103.

16. Chaboche J. L., Lesne P. M. (1988), A non-linear continuous fatigue damage model, Fatigue and Fracture of Engineering Materials and Structures, 11, 1, 1-7.

17. Coffin L. F. (1956), Design aspects of high-temperature fatigue with particular reference to thermal stresses, Transactions of the ASME, $78,527-532$.

18. Corten H. T., Dolon T. J. (1956), Cumulative fatigue damage. In Proceedings of the International Conference on Fatigue of Metals, Institution of Mechanical Engineering and American Society of Mechanical Engineers, 235-246.

19. Dubuc J., Bui-Quoc T., Bazergui A., Biron A. (1971), Unified theory of cumulative damage in metal fatigue. W.R. C. Bulletin, 162, $1-20$.

20. Dunne F., Petrinic N. (2005), Introduction to Computational Plasticity,Oxford University Press, New York

21. French H. J. (1933), Fatigue and hardening of steels, Transactions, American Society of Steel Treating, 21, 899-946.

22. Freudenthal A. M. (1956), Physical and statistical aspects of cumulative damage, Springer-Verlag, Berlin, 53-62.

23. Freudenthal A. M., Heller R. A. (1959), On stress interaction in fatigue and a cumulative damage rule, Journal of the Aerospace Sciences, 26, 7, 431-442.

24. Gatts R. R. (1961), Application of a cumulative damage concept to fatigue, ASME Journal of Basic Engineering,83,529-540.

25. Gatts R. R. (1962), Cumulative fatigue damage with random loading, ASME Journal of Basic Engineering, 84, 403-409.

26. Glinka G, Shen G, Plumtree A. (1995), A multiaxial fatigue strain energy density parameter related to the critical plane, Fatigue Fract Eng Mater Struct; 18:37-46.

27. Golos K., Ellyin F. (1987), Generalization of cumulative damage criterion to multilevel cyclic loading, Theoretical and Applied Fracture Mechanics, 7, 169-176.

28. Golos K., Ellyin F. (1988), A total strain energy density theory for cumulative fatigue damage, ASME Journal of Pressure Vessel Technology, 110, 36-41.

29. Golos K., Ellyin F. (1989), Total strain energy density as a fatigue damage parameter, In Advances in Fatigue Science and Technology, Proceedings of the NATO Advanced Study Institute, cd. C. M. Branco and L. G. Rosa. Kluwer Academic, 849-859. 
30. Grover H. J. (1960), An observation concerning the cycle ratio in cumulative damage, American Society for Testing and Materials, Philadelphia, PA , 120-124

31. Halford G. R. (1966), The energy required for fatigue, Journal of Materials, 1(1), 3-18.

32. Halford G. R., Manson S. S. (1985), Reexamination of cumulative fatigue damage laws, In Structure Integrity and Durability of Reusable Space Propulsion Systems, NASA CP-2381. NASA, 139-145.

33. Henry D. L. (1955), A theory of fatigue damage accumulation in steel, Transactions of the ASME, 77, 913-918.

34. Hua C. T., Socie D., F. (1984), Fatigue damage in 1045 steel under constant amplitude biaxial loading, Fatigue of Engineering Materials and Structures, 7, 3, 165-179

35. Inglis N. P. (1927), Hysteresis and fatigue of Wohler rotating cantilever specimen, The Metallurgist, 23-27.

36. Kachanov L. M. (1969), Time to the rupture process under creep conditions, Izvestiia AN SSSR, 1984, OTN(8), 26-31.

37. Kommers J. B. (1945), The effect of overstress in fatigue on the endurance life of steel, Proceedings, American Society for Testing and Materials, 45, 532-541.

38. Kujawski D., Ellyin F. (1984), A cumulative damage theory of fatigue crack initiation and propagation, International Journal of Fatigue, 6, 2, 83-88.

39. Lagoda T. (2001), Energy models for fatigue life estimation under uniaxial random loading. Part I: The model elaboration. Int. J. Fatigue; 23:467-80.

40. Langer B. F. (1937), Fatigue failure from stress cycles of varying amplitude, ASME Journal of Applied Mechanics, 59, Al60-Al62.

41. Leis B. N. (1988), A nonlinear history-dependent damage model for low cycle fatigue, Low Cycle Fatigue, ASTM STP 942.

42. Leis B. N. (1997), An energy-based fatigue and creep-fatigue damage parameter, Journal of Pressure Vessel and Technology, ASME Transactions, 99(4), 52-+-533.

43. Lemaitre J., Chaboche J. L. (1978), Aspect phenomenologique de la ruptutre par endommagement, Journal Mecanique Appliquee, 2(3), 317-365.

44. Lemaitre J., Plumtree A. (1979), Application of damage concepts to predict creep-fatigue failures, ASME Journal of Engineering Materials and Technology, 101, 284-292.

45. Lemaitre J., Chaboche J. L. (1990), Mechanics of Solid Materials, trans. B. Shrivastava, Cambridge University Press, Cambridge, UK.

46. Li C., Qian Z. and Li G. (1989), The fatigue damage criterion and evolution equation containing material microparameters, Engineering Fracture Mechanics, 34(2), 435-443.

47. LLorca J. (2002), Fatigue of particle-and whisker-reinforced metalmatrix composites, Progress in Materials Science, 47, 283-353.

48. Machlin E. S. (1949), Dislocation theory of the fatigue of metals, N.A.C.A. Report 929

49. Manson S. S. (1966), Interfaces between fatigue, creep, and fracture, International Journal of Fracture Mechanics, 2, 328-363.

50. Manson S. S., Halford G. R. (1981), Practical implementation of the double linear damage rule and damage curve approach for treating cumulative fatigue damage, International Journal of Fracture, 17(2), 169-192.

51. Manson S. S., Halford G. R. (1983), Complexities of hightemperature metal fatigue: some steps toward understanding, Israel Journal of Technology, 21, 29-53.

52. Marco S. M., Starkey W. L. (1954), A concept of fatigue damage, Transactions of the ASME, 76, 627-632.

53. Miner M. A. (1945), Cumulative damage in fatigue. Journal of Applied Mechanics, 67, Al59-Al64.

54. Morrow J. D. (1965), Cycle plastic strain energy and fatigue of metals. In Internal Friction, Damping, and Cyclic Plasticity, ASTM STP 378, American Society for Testing and Materials, Philadelphia, $\mathrm{PA}, 45-84$.
55. Niu X. D. (1987), Memory behavior of stress amplitude responses and fatigue damage model of a hot-rolled low carbon steel. In Mechanical Behavior of Materials-V, Proceedings of the Fifth International Conference, Vol. 1, ed. M. G. Yan, S. H. Zhang and Z. M. Zheng., Pergamon Press, Oxford, 685-690.

56. Niu X., Li G. X., Lee H. (1987), Hardening law and fatigue damage of a cyclic hardening metal, Engineering Fracture Mechanics, 26(2), 163-170.

57. Palmgren A. (1924), Die Lebensdauer von Kugellagern, Veifahrenstechinik, Berlin, 68, 339-341.

58. Plumtree A. and O'Connor B. P. D. (1989), Damage accumulation and fatigue crack propagation in a squeeze-formed aluminum alloy, International Journal of Fatigue, 11, 4, 249-254.

59. Rabotnov Y. N. (1969), Creep Problems in Structural Members, North-Holland, Amsterdam.

60. Radhakrishnan V. M. (1978), Cumulative damage in low-cycle fatigue, Experimental Mechanics, 18, 8, 292-296.

61. Radhakrishnan V. M. (1980), An analysis of low cycle fatigue based on hysteresis energy, Fatigue of Engineering Materials and Structures, 3, 75-84.

62. Richart F. E., Newmark N. M. (1948), A hypothesis for the determination of cumulative damage in fatigue, Proceedings, American Society for Testing and Materials, 48, 767-800.

63. Seweryn A, Buczyński A, Szusta J. (2008), Damage accumulation model for low cycle fatigue, Int. J. Fatigue, 1, 30:756-65.

64. Shanley F. R. (1952), A theory of fatigue based on unbonding during reversed slip, Report P-350, The Rand Corporation, Santa Monica.

65. Socie D. F., Fash J. W., Leckie F. A. (1983), A continuum damage model for fatigue analysis of cast iron, In Advances in Life Prediction Methods, ed, D. A. Woodford and J, R. Whitehead, The American Society of Mechanical Engineers, New York, 59-64.

66. Sutton Ch. E. (2009), Fatigue damage assessment of particlereinforced metal matrix composite materials under uniaxial and multiaxial loadings conditions, Digital Commons @ Ryerson, Toronto, Ontario.

67. Tamura I., Tomota Y., Ozawa H. (1973), Strength and ductility of $\mathrm{Fe}-\mathrm{Ni}-\mathrm{C}$ alloys composed of austenite and martensite with various strength, Proceedings of the Third International Conference on Strength of Metals and Alloys, Vol. 1. Cambridge: Institute of Metals; 611-5.

68. Valluri S. R. (1961), A unified engineering theory of high stress level fatigue, Aerospace Engineering, 20, 18-19.

69. Valluri S. R. (1961), A theory of cumulative damage in fatigue. Report No. ARL 182, Aeronautical Research Laboratory, Office of Aerospace Research, United States Air Force.

70. Weinacht D. J., Socie D. F. (1987), Fatigue damage accumulation in grey cast iron, International Journal of Fatigue, 9, 2, 79-86.

71. Wheeler O. E. (1972), Spectrum loading and crack growth, ASME Journal of Basic Engineering, D94(1), 181-186.

72. Willenborg J., Engle R. M., Wood H. A. (1971), A crack growth retardation model using an effective stress concept, AFFDL TM71-IFBR.

73. Williamson R. L., Rabin B. H., Drake J. T. (1993), Finite Element Analysis of Thermal residual Stresses at Graded Ceramic-Metal Interface, Part I. Model Description and Geometrical Effects, J. Appl. Phys., Vol. 74, 2, 13010-1320.

74. Zuchowski R. (1989), Specific strain work as both failure criterion and material damage measure, Res Mechanica, 27(4), 309-322.

Acknowledgment: The results presented in this paper have been obtained within the project "KomCerMet" (contract no. POIG.01.03.01-14013/08-00 with the Polish Ministry of Science and Higher Education) in the framework of the Operational Programme Innovative Economy 2007-2013 and within the EU FP7 Project "Micro and Nanocrystalline Functionally Graded Materials for Transport Applications" (MATRANS) under Grant Agreement no. 22886. 